\title{
Assessment of Serum Ferritin, Vitamin B12 and Folic Acid Level in Thalassemia
}

\author{
Authors \\ Dr Neha Sharma ${ }^{1}$, Dr Ankur Gupta ${ }^{2}$, Dr Garima Gupta ${ }^{3}$ \\ ${ }^{1}$ Department of Biochemistry and Department of Pathology SMS Medical College Jaipur \\ ${ }^{2}$ Medical Officer, Govt District Shri Kalyan Chikitsalaya, Sikar, Rajasthan \\ ${ }^{3}$ Assistant Consultant, Obs and Gynae Department, Ruchika Nursing Home, Sikar, Rajasthan \\ Corresponding Author \\ Dr Ankur Gupta
}

Address: E 132 Sector 2 Chitrakoot Yojna,Vaishali Nagar, Jaipur, Rajasthan

Email:draaankur.100@gmail.com

\begin{abstract}
Objective: To assess the levels of serum ferritin, vitamin B12,folic acid in thalassemic children.

Material and Methods: This study was carried out in the Department of Biochemistry in SMS Medical college Jaipur. Thirty children with the confirmed diagnosis of thalassemia were enrolled in the study group and thirty healthy age and sex matched children were included in the control group. Estimation of serum ferritin, folic acid and vitamin B12 were done by ADVIA Centaur XP autoanalyzer by chemiluminescence immunoassay.

Results: Study group showed a decrease in serum folic acid and vitamin B12 levels with mean value of 3.71 $\pm 1.17 \mathrm{ng} / \mathrm{mL}$ and $163.6 \pm 31.31 \mathrm{pg} / \mathrm{mL}$ respectively as compared to control group was $11.03 \pm 3.84 \mathrm{ng} / \mathrm{mL}$ and $439.33 \pm 127.6 \mathrm{pg} / \mathrm{mL}(\mathrm{p}<0.001)$ whereas increased concentration of ferritin with mean value of $2144.7 \pm 330.8$ $n g / m L$ in study group as compared to control group was $198.9 \pm 66.9$ and was statistically highly significant $(p<0.001)$.

Conclusion: The present study found a significant decrease of vitamin B12, folic acid and increased ferritin in children with thalassemia. Biochemical screening of these parameters is of paramount importance in thalassemia patients in paediatric age group. Also, there is an absolute need for further studies to understand the mechanism of relationship between serum ferritin, Vitamin $B 12$ and folic acid in these patients.

Keywords:Thalassemia; Ferritin; vitamin B12; Folic acid.
\end{abstract}

\section{Introduction}

The Thalassemia syndromes are inherited disorders of $\alpha$ - or $\beta$-globin biosynthesis. The reduced supply of globin diminishes production of hemoglobin tetramers, causing hypochromia and microcytosis. Unbalanced accumulation of $\alpha$ and $\beta$ subunits occur because the synthesis of the unaffected globins proceeds at a normal rate. Clinical severity varies widely, depending on the degree to which the synthesis of the affected globin is impaired, altered synthesis of other globin chains, and coinheritance of other abnormal globin alleles. The Thalassemias (named from the Greek word for sea, thalassa) ${ }^{1}$ are a group of inherited autosomal recessive hematologic disorders ${ }^{2}$ that cause hemolytic anemia because of the decreased or absent 
synthesis of a globin chain. Imbalances of globin chains cause hemolysis and impair erythropoiesis. Thalassemias are the most common genetic disorders in the world, affecting nearly 200 million people worldwide. The total annual incidence of symptomatic individuals is estimated at 1 in 100,000 throughout the world and 1 in 10,000 people in the European Union. However, accurate data on carrier rates in many populations are lacking, particularly in areas of the world known or expected to be heavily affected ${ }^{3}$. According to Thalassemia International Federation, only about 200,000 patients with Thalassemia major are alive and registered as receiving regular treatment around the world ${ }^{4}$.

Approximately 5 percent of the world's population has a globin variant, but only 1.7 percent has alpha or beta Thalassemia trait. $\beta-$ Thalassemia is the most common genetically transmitted hematological disorder in Indian children ${ }^{5}$.

\section{Materials and Methods}

This study was carried out in the Department of Biochemistry in SMS Medical college Jaipur. Thirty (30) children with the confirmed diagnosis of thalassemia were enrolled in the study group and thirty healthy age and sex matched children who had never anemia were included in the control group. Estimation of serum ferritin, folic acid and vitamin B12 were done by ADVIA Centaur XP autoanalyzer by chemiluminescence immunoassay6-8.

Inclusion criteria were normal renal and liver function. Exclusion criteria were use of medication (iron chelating agent therapy, phenytoin, carbamazepine, antifolates, theophylline, tamoxifen), diabetes mellitus, carcinoma, anemia.

\section{Results}

In our study, Thalassemic patients had much higher ferritin levels in comparison with healthy controls. Study group showed a decrease in serum folic acid and vitamin B12 levels with mean value of $3.71 \pm 1.17 \mathrm{ng} / \mathrm{mL}$ and $163.6 \pm 31.31 \mathrm{pg} / \mathrm{mL}$ respectively as compared to control group was $11.02 \pm 3.84 \mathrm{ng} / \mathrm{mL}$ and $439.33 \pm 127.62 \mathrm{pg} / \mathrm{mL}$ $(\mathrm{P}<0.001)$ whereas increased concentration of ferritin with mean value of $2144.7 \pm 330.799$ $\mathrm{ng} / \mathrm{mL}$ in study group as compared to control group was $198.9 \pm 66.95$ and was statistically highly significant $(\mathrm{p}<0.001)$.

Table 1: Mean \pm SD of Serum Ferritin in cases and control group subjects

\begin{tabular}{|l|c|c|c|c|c|}
\hline Group & N & Mean & SD & P-Value & Significance \\
\cline { 1 - 4 } Control & 30 & 198.9 & 66.95 & \multirow{2}{*}{$<0.001$} & HS \\
\cline { 1 - 4 } Case & 30 & 2144.7 & 330.799 & & \\
\hline
\end{tabular}

HS - Highly Significant

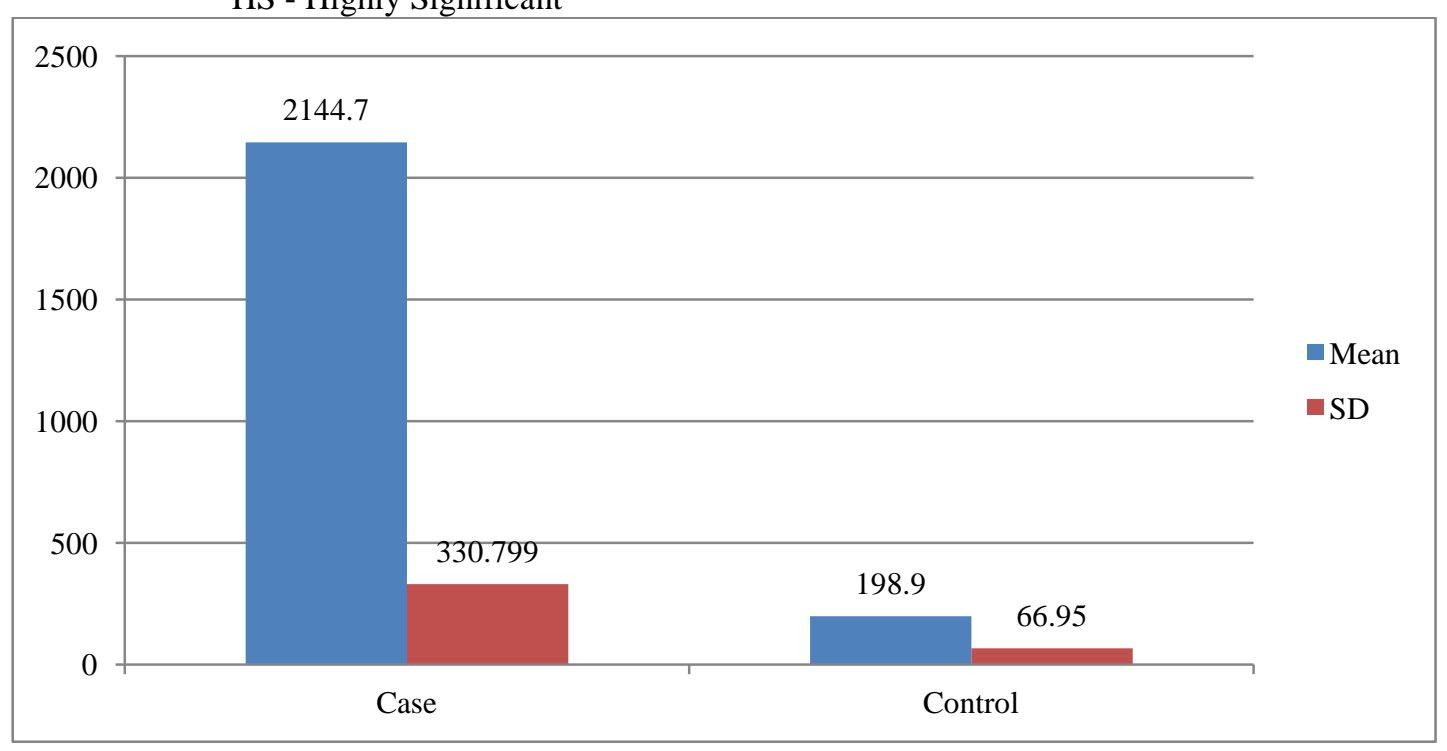

Graph showing Mean \pm SD of Serum Ferritin in cases and control group subjects 
Table 2 :Mean \pm SD of Vit-B12 in cases and control group subjects

\begin{tabular}{|l|c|c|c|c|c|}
\hline Group & $\mathrm{N}$ & Mean & SD & P-Value & Significance \\
\hline Control & 30 & 439.33 & 127.62 & \multirow{2}{*}{$<.0 .001$} & HS \\
\hline Case & 30 & 163.6 & 31.31 & & \\
\hline
\end{tabular}

HS - Highly Significant

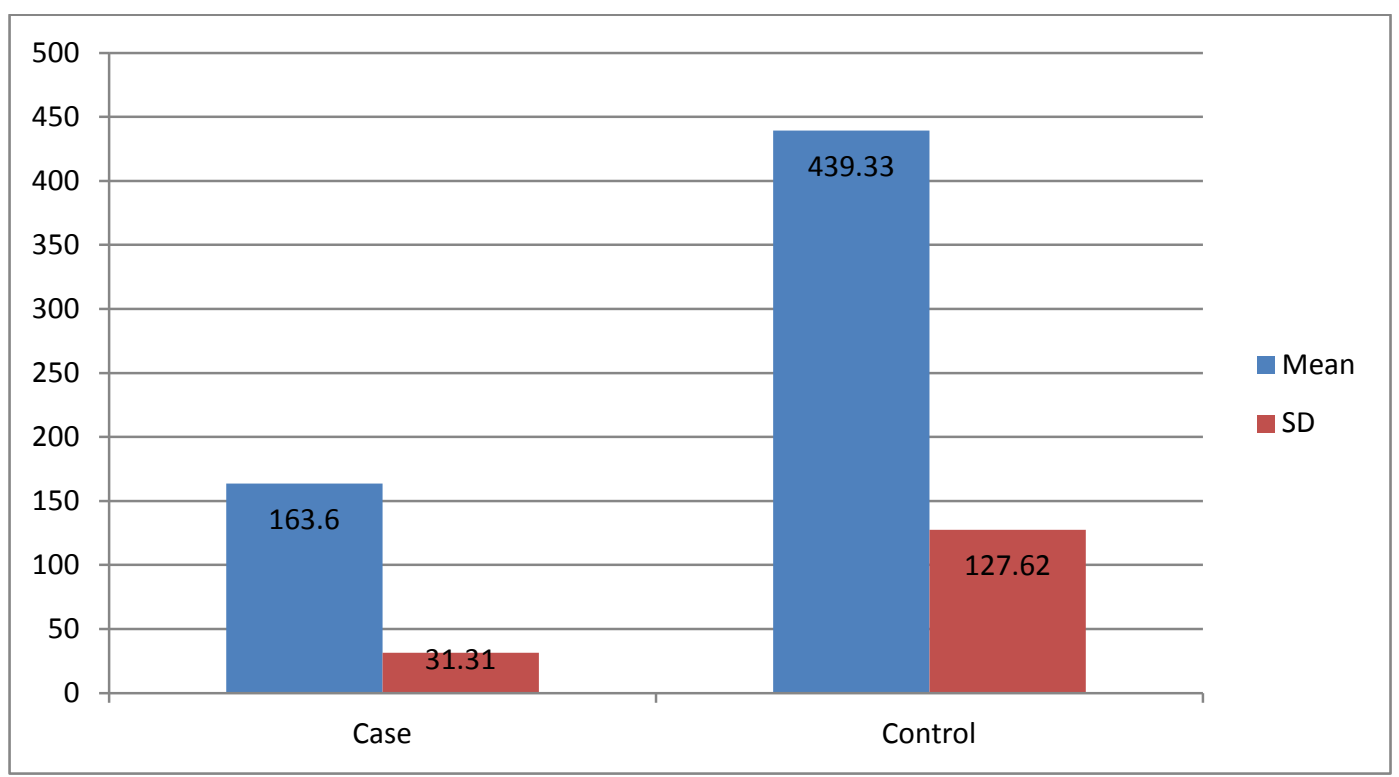

Graph showing Mean \pm SD of Vit-B12 in cases and control group subjects

Table 3: Mean \pm SD of Serum Folic Acid in cases and control group subjects

\begin{tabular}{|l|c|c|c|c|c|}
\hline Group & $\mathrm{N}$ & Mean & SD & P-Value & Significance \\
\hline Control & 30 & 11.03 & 3.84 & \multirow{2}{*}{$<0.001$} & HS \\
\hline Case & 30 & 3.71 & 1.173 & \\
\hline
\end{tabular}

HS - Highly Significant

Graph showing Mean \pm SD of Serum Folic Acid in cases and control group subjects

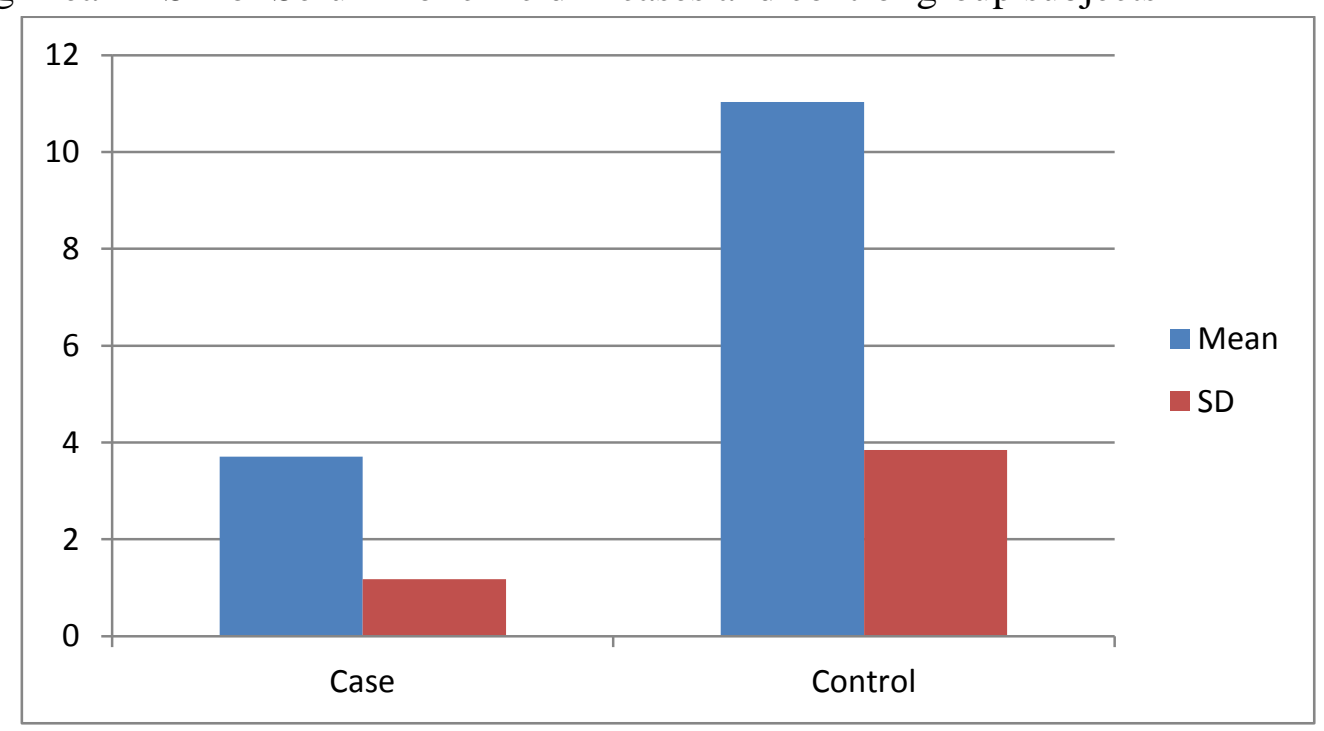

\begin{tabular}{|l|c|c|c|c|}
\hline Parameters & Study Group & Control group & $P$-value & Significance \\
\hline Serum Folic Acid(ng/mL) & $3.71+1.17$ & $11.03+3.84$ & $(P<0.001)$ & HS \\
\hline Serum Vitamin B12 $(\mathrm{pg} / \mathrm{mL})$ & $163.6+31.31$ & $439.33+127.6$ & $(P<0.001)$ & HS \\
\hline Serum Ferritin $(\mathrm{ng} / \mathrm{mL})$ & $2144.7+330.79$ & $198.9+66.9$ & $(P<0.001)$ & HS \\
\hline
\end{tabular}


Our studies showed that serum ferritin level of thalassemia patients were much higher than normal healthy controls. Also a highly significant decreased folic acid levels was observed in the paediatric age group as compared to the control group.

Our study indicates that deficiency of folic acid in thalassemia subjects. Vitamin B12 deficiency also seen in our study group as compared with controls. Mean concentrations of vitamin B12 decline and was highly significant in thalassemic group. Our observations are also supported by some previous studies9.

\section{Discussion}

Bala J et al( 2015), the study group showed a decrease in serum folic acid and vitamin B12 levels as compared to control group whereas increased concentration of ferritin in study group as compared to control group and this was statistically highly significant $(\mathrm{p}<0.001) .{ }^{10}$

Another study by Vinayak W. Patil et al in( 2012) elucidated the relationship between serum ferritin with vitamin B especially folic acid and vitamin B12. A negative and significant correlation $(r=-$ $0.4836, \mathrm{p}<0.001$ ) was observed between serum ferritin and folic acid in study subjects. Correlation between the serum ferritin and vitamin B 12 was analyzed statistically. The serum ferritin was found to have significantly negative correlation $(r=-0.7245, p<0.001)$ with the serum vitamin B12 in all $\beta$ thalassemia patients. ${ }^{11}$

Warbach MR (2008) have reported food and nutrient intake differences between $\beta$ thalassemia and healthy subjects ${ }^{11}$. They also observed $\beta$ thalassemic patients have a lower intake of most vitamins and were less likely to have consumed fruit, vegetables, vitamins and mineral supplements. $^{12}$

Negative relationship between serum ferritin and serum vitamin B12 may be due to increased concentration of $\mathrm{Hb}$ A2 previously studied by Henshaw et al, Silva et al (1989) and Kumar R (1985) supports these good correlations. In our study measurement of exact concentration of $\mathrm{Hb}$
A2 is remain behind because of urgent $\mathrm{Hb}$ electrophoresis are not available during the study. 13-15

Kumar et al (1985) concluded that diagnosis of folate and vitamin B12 deficiencies in HBT cannot be based on serum B12, SF and RCF estimation. To accurately determine the deficiency of these vitamins, a therapeutic trial with folate and or B12 is recommended. Besides the globin chain synthesis defect, iron overload also contributes to severity of anemia. ${ }^{15}$

\section{Conclusion}

The present study found a significant decrease of vitamin B12, folic acid and increased ferritin in children with thalassemia. Biochemical screening of these parameters is of paramount importance in thalassemia patients in paediatric age group. Also, there is an absolute need for further studies to understand the mechanism of relationship between serum ferritin, Vitamin B12 and folic acid in these patients. However, therapy can be given to minimize further complication of vitamin B12 and folic acid deficiency. The problems of poverty, low education level and inadequate provision of health care are the main stumbling blocks in effective treatment of thalassemic patients of iron over load the complications of which are the main cause of morbidity and mortality in thalassemia major.

\section{References}

1. Whipple GH, Bradford WL. Mediterranean disease: thalassemia (erythroblastic anemia of Cooley). $J$ Pediatr. 1936;9:279-311.

2. Rund D, Rachmilewitz E. Beta-thalassemia. $N$ Engl J Med. 2005;353(11):11351146.

3. Vichinsky EP: Changing patterns of thalassemia worldwide. Ann N Y Acad Sci 2005, 1054:18-24.

4. Thalassemia International Federation: Guidelines for the clinical management of 
thalassemia 2nd edition. 2008 [http:// www.thalassemia.org.cy].

5. Maheshwari M, Sadhna A, Kabra M, Menon PSN. Carrier screening and prenatal diagnosis of Beta-Thalassemia. Ind Paediatr 1999; 36 (11): 1119-1125.

6. Alfrey CP. Serum ferritin assay. CRC Crit Rev Clin Lab Sci 1978;9:179-208.

7. McNeely MDD. Folic acid assay. In Kaplan LA, Pesce AJ,(eds). Clinical Chemistry. St. Louis: CV Mosby, 1984:1402-6

8. Allen RH. Clinical role and current status of serum cobalamine (vitamin B12) assays. Ligand Quaterly 1981;4;37-44.

9. Tamagnini GP, Lopes MC, Castenheira ME, Wainscoat JS, Wood WG. $\beta$ thalassemia-Portguise type: Clinical, haematologial and molecular studies of a newly defined form of $\beta$ thalassemia. $\mathrm{Br} \mathrm{J}$ Haematol 1983;54:189- 200.

10. Bala J, Saurabh K, Ghalaut VS, Aggrawal Y. Study the levels of folic acid, vitamin B12 and ferritin in thalassemia. J Pharm Biomed Sci. 2015; 05(07):539-541

11. Vinayak W. Patil and Shahid A. Mujawar. Deficiency of folic acid, vitamins B 12 and their correlation with ferritin in childhood $\beta$-thalassemia major. Indian $\mathrm{J}$ Bioc Sci. 2010; Vol. 14, No. 2 (2010-07 - 2010-12)

12. Werbach MR. Nutritional Imbalances in Anemia. Townsend Letter 2008: 119-120.

13. Henshaw LA, Tizzard JL, Booth K, Beard MEJ. Haemoglobin A2 levels in vitamin B12 and folate deficiency. J ClinPathol 1978; 31: 960-962

14. Silva AE, Varella-Garcia M. Plasma folate and vitamin B12 levels in beta-thalassemia heterozygotes. Braz J Med Biol Res 1989; 22 (10):1225-1228.

15. Kumar R , Saraya AK, Choudhyr VP, Sundaram KR, Kailash S, Sehgal AK. Vitamin B12, folate, and iron studies in homozygous beta thalassemia. Am J Clin Pathol 1985; 84 (5): 668-671. 